\title{
Promoting Children's Mental Health in Family Supportive Housing: A Community-University Partnership for Formerly Homeless Children and Families
}

\author{
Abigail H. Gewirtz
}

Published online: 13 June 2007

(C) Springer Science+Business Media, LLC 2007

\begin{abstract}
Emerging research indicates that significant numbers of formerly homeless families residing in permanent supportive housing have caregivers with substance use and mental health disorders, and children with histories of exposure to violence, abuse, and out-of-home placement. These factors place children at risk for adverse psychosocial outcomes, including later homelessness, providing a strong rationale for embedding child-focused prevention and intervention services in supportive housing contexts. This article describes a developing community-university partnership whose goal is to advance practice and research in the adaptation and dissemination of mental health prevention and early intervention for children in supportive housing.
\end{abstract}

Keywords Family supportive housing · Children · Mental health ·

Prevention · Community-university partnership

\section{Introduction}

Family homelessness has increased significantly in recent years (e.g., Burt et al. 2001), and families with children account for an estimated $40 \%$ of homeless households (U.S. Conference of Mayors 2004). Studies of families in shelters and in the community indicate that homeless children face a greater likelihood than poor housed children of experiencing hunger, multiple school placements, exposure to violence, and maltreatment (e.g., Anooshian 2005; Gewirtz and Edleson, in press; Masten et al. 1993), parental substance abuse, and/or parental mental illness (Bassuk et al. 1996, 1997; Burt et al., 1999; McQuistion et al. 2003; Vostanis et al. 1997). A subset of these children also have experienced out-of-home placement by child

\footnotetext{
A. H. Gewirtz $(\bowtie)$

Department of Psychiatry, University of Minnesota, F-261 West, 2450 Riverside Ave,

Minneapolis, MN 55454, USA

e-mail: agewirtz@umn.edu
} 
protection authorities or through voluntary placement by parents with housed relatives (Shinn et al. 2006). Some studies have failed to find individual psychosocial factors that distinguish homeless families in general from poor housed families (e.g., Burt et al. 2001; Shinn et al. 1998). However, recent prospective longitudinal data indicate that adult caregivers in repeatedly homeless families are significantly more likely to have been exposed to childhood and adulthood traumatic experiences than are caregivers in families characterized by a single episode of homelessness (Bassuk et al. 2001).

Decades of research have demonstrated the negative impact of homelessness on children's health and social, emotional, behavioral, and academic functioning (e.g., Rafferty and Shinn 1991; Weinreb et al. 1998). Moreover, the impact of homelessness appears to extend beyond the period of homelessness itself. For example, Masten et al. (1993) compared children in homeless families residing in a shelter with a socio-demographically matched group of very poor, housed children and found that homeless children faced more recent adverse life events, were more likely to have externalizing and/or internalizing problems in the clinical range, and had more impaired school functioning. Moreover, the subgroup of formerly homeless children in the poor housed group displayed significantly more internalizing and externalizing problems than the rest of the housed group, similar to the homeless children. Vostanis et al. (1998), followed a group of 58 homeless families for a year following shelter stay. Even though all families were housed at follow-up, formerly homeless children had more complex, and greater numbers of mental health problems than those of a socio-demographically matched group of never-homeless children.

\section{Family Supportive Housing}

Supportive housing, which combines rental subsidies with support services for homeless families (Corporation for Supportive Housing 2005) has become an increasingly utilized option to end family homelessness. There are no official estimates of the number of supportive housing units nationwide or the numbers of families or children resident within them, although informal estimates suggest about 75,000 units. Supportive housing became formalized with the McKinney Homelessness Act in 1987. In 1993, federal funding through the US Department of Housing and Urban Development (HUD) was allocated to permanent supportive housing for families with disabilities (primarily mental illness, chemical dependence and HIV/AIDS). Since 2003, allocation of supportive housing resources has been limited to households with persons with disabilities who also meet criteria for chronic homelessness, defined as twelve consecutive months of homelessness, or four episodes in the last 3 years. These criteria suggest that families in supportive housing may have significant histories of risk and adversity, providing a rationale for the urgency to learn more about the status and needs of children in these settings.

Most studies of supportive housing have, however, been limited to investigating the status, resources, programs, and outcomes of single adults, for whom supportive housing was originally designed (e.g., Schinka et al. 1998). These studies generally 
provide support for the utility of supportive housing for single mentally ill adults (e.g., Culhane et al. 2002; Lipton et al. 2000). The use of rental subsidies has been shown to be important for residential stability, across both single adults and families (e.g., Shinn et al. 1998). Very little has been published on family supportive housing, although initial reports indicate that family supportive housing may increase residential stability and that adult caregivers report satisfaction with housing (Hanrahan et al. 2005; Nolan et al. 2005). No published data could be found regarding the mental health status of children in supportive housing environments, or the resources available to address their psychosocial needs, although the increasing number of children in such housing environments has been noted (e.g., McQuistion et al. 2003).

We recently reported the results of a descriptive study of the psychosocial status of 454 children living in 17 single-site family supportive housing communities in a large Midwest metropolitan area (Gewirtz, Hart-Shegos, \& Medhanie, in press). Reports from housing case managers and parents indicated that these formerly homeless children had experienced multiple disruptions: $37 \%$ of resident families reported current or prior involvement in Child Protective Services for abuse or neglect; more than two-thirds of parents had diagnosed mental illness or substance use disorders, and providers reported that $70-95 \%$ of their child residents had witnessed intimate partner violence. ${ }^{1}$ Children were exhibiting significant emotional, behavioral, and academic difficulties. Overall, $15 \%$ of birth to 4-year-olds, $47 \%$ of 5- to 11 -year-olds, and $67 \%$ of 12 - to 18 -year-olds were reported to present with an emotional, behavioral, or learning problem. Thirty-nine percent of elementary-aged children (5- to 11-year-olds) and $45 \%$ of 12- to 18-year-olds were reported to be below grade level in reading or mathematics. Behavior problems resulted in $28 \%$ of elementary-aged children and $52 \%$ of adolescents having been suspended and/or expelled from school at least once. Case managers and parents also reported significant numbers of children with internalizing difficulties, with $12 \%$ of young children, $20 \%$ of elementary-aged children, and $35 \%$ of adolescents seeming depressed or anxious. (It is noteworthy, however, that child self-report data were not gathered, which may limit the findings with regard to children's internalizing difficulties.)

Data collected simultaneously from surveys of and about housing programs in which families were resident, indicated that the housing case managers were confident in their provision of concrete services to adults and families (i.e., facilitating access to jobs, education, benefits, healthcare coverage, and routine/ general medical care), but often felt that they lacked the resources to meet children's specialized mental health needs. Licensed mental health professionals (serving either children or adults) provided limited onsite services in only $25 \%$ of the programs. Independent observer ratings by outside community mental health professionals not affiliated with the housing programs indicated low housing provider expertise in accessing and navigating children's mental health resources

\footnotetext{
1 This question was asked of providers and not parents, and was only asked in a subgroup of agencies. The question was asked during interviews with staff by outside mental health professionals from a community agency who were assessing internal needs and capacities of provider agencies.
} 
for their clients. Only two of the 17 housing communities reported any experience with the provision of evidence-based children's mental health and substance abuse prevention or treatment for their clients. ${ }^{2}$

In contrast to the lack of knowledge and resources in regard to mental health, survey respondents did indicate high rates of children's healthcare coverage and routine medical care: $95 \%$ of the children had medical insurance; $97 \%$ of the children were up-to-date with their immunizations, and $94 \%$ were attending regular well-child checkups, according to case managers and parents.

Although this cannot be inferred from the study data, effective case management in supportive housing is likely facilitating these extremely high rates of healthcare coverage and well-child visits. The lack of children's mental health resources is not surprising given that (a) single adults (and not families) were historically the target population for supportive housing (e.g., Hopper and Barrow 2003; Tsemberis 1999), (b) the mental health needs of children in supportive housing have not previously been documented, and (c) the children's mental health system is a complex, subspecialty care system, with a dearth of providers and of child- and family-focused services. Indeed, data indicated that case managers were familiar with the adult mental health and substance abuse service systems, consistent with the documented significant proportions of mental and chemical health diagnoses among adult residents (Gewirtz, Hart-Shegos, \& Medhanie, in press). The high rates of mental health concerns combined with the backgrounds of psychosocial risks faced by children suggested a need for increased attention within family supportive housing toward infrastructure and provider resources in child development and children's mental health.

The combination of the descriptive data reported above, earlier studies indicating the adversity experienced by repeatedly homeless families, and the current federal guidelines limiting family supportive housing to a particularly high-risk subgroup of homeless families, all serve to emphasize the psychosocial needs of children in family supportive housing. Moreover, the fact that supportive housing incorporates support services, provides a unique and timely opportunity to offer and broker evidence-based interventions to promote children's mental health. Such programming is critical for preventing and ameliorating the effects of exposure to homelessness-related traumatic events (e.g., displacement, abuse, partner violence, foster placement) and related risk factors (parental substance abuse and mental illness), as well as promoting competence in developmental tasks through familybased interventions. Prevention programs have effectively targeted both the correlates of homelessness in childhood and the precursors of homelessness in adulthood (e.g., maltreatment and foster placement: Olds 2002; substance abuse: August et al. 2004).

\footnotetext{
${ }^{2}$ Evidence-based practices are defined here, consistent with current literature, as those based on research evidence, that have been denoted as effective or promising according to current standards of prevention research (e.g., shown to be effective in at least a single randomized efficacy trial). For more information, see, for example, www.modelprograms.samhsa.gov.
} 


\section{The Healthy Families Network}

The Healthy Families Network (HFN) is a developing community-university collaboration whose overall goal is to advance both service and science by (i) promoting the mental health of children in family supportive housing, and (ii) advancing a prevention research agenda for high-risk, formerly homeless children and families. The HFN is a collaborative endeavor between 17 independent, nonprofit organizations with supportive housing programs, the Family Housing Fund (a non-profit housing intermediary whose mission is to produce and preserve affordable housing in the Twin Cities metropolitan area), and researchers at the University of Minnesota. The housing agencies comprising the HFN serve 600 families with over 1,200 children each year, and represent approximately $90 \%$ of the formerly homeless families resident in single-site family supportive housing in a seven-county metropolitan area of more than 2.5 million people. HFN agencies are quite diverse in their missions, target populations, and criteria for admission, but most of the agencies provide permanent family supportive housing. ${ }^{3}$ Although the Healthy Families Network's programmatic focus is single-site family supportive housing, several of its member agencies also have scattered site-housing units, and additionally serve single adults. HFN agencies each house from 12 to 57 families in single-site apartment buildings. Criteria for admission vary across agencies, but include family homelessness, and in addition, a parental mental health, or substance use disorder, HIV infection, and/or a mother and children fleeing domestic violence or prostitution. Staffing patterns vary across HFN sites, but most commonly, sites offer case management services to support families to maintain their housing, manage finances, access jobs, education and/or training, access health insurance, routine medical services, and other needed community resources. Some agencies have child advocates who provide childcare and some offer after-school programming. Case managers typically have excellent experience accessing community resources and facilitating referrals, and the exceptionally high rates of health coverage among residents (noted earlier; Gewirtz, Hart-Shegos, \& Medhanie, in press) may be a testament to case managers' efficiency in accessing insurance for families.

The HFN was initiated several years ago after member agencies voiced concerns about their capacity to meet the increasing incidence of behavioral and emotional problems among formerly homeless resident children. The providers and the Family Housing Fund initially approached researchers at the University of Minnesota to request training in children's mental health, and the developing partnership has since evolved, as described below.

\footnotetext{
${ }^{3}$ One of the agencies is technically a shelter, with a 6 month maximum length of stay, but is a partner in the HFN as it is the only supportive housing provider in the county it serves; four others are considered transitional housing, with a maximum of 24 months length of stay, and 12 agencies have permanent supportive housing programs. All 17 organizations consider themselves supportive housing providers, as providers of housing with onsite support services.
} 


\section{Principles of the HFN Partnership}

The HFN community-university partnership adheres to community-based participatory research (CBPR) principles (also known as participatory action research; Kidd and Kral 2005; Tolan et al. 1990). Hughes (2003) suggests that the goal of participatory research is "to build a community's capacity to solve self-identified problems and to promote health and social justice"' (p. 41). In the CBPR paradigm, the community partners generate research questions, and community members and researchers share control of the study. Collection and analysis of the data are carried out jointly, and the community drives how the knowledge will be used (e.g., what new practices may be implemented). Researchers provide training and technical assistance on the practices selected for implementation by the community, but ownership of the practices is assumed to belong to the community (Spoth and Redmond 2002; Weissberg and Greenberg 1998).

\section{Partnership Structure and Roles}

The HFN project is driven by an Advisory Committee comprised of representatives of the housing agencies, staffed by a Family Housing Fund consultant. The Advisory Committee develops the project priorities, reviews results of the research, reviews progress, and makes recommendations to the entire group about new directions. The role of university researchers in this project is twofold: (i) to advance research on mental health preventive and treatment services within family supportive housing by designing studies in collaboration with providers, securing research funding, and disseminating research results and, (ii) to provide ongoing training and technical assistance on evidence-based, family-focused practice in children's mental health, and developmental psychopathology. The Family Housing Fund, which has provided capital project support to the individual HFN providers over the past 10 years, serves as fiscal agent for the HFN project, providing a communication, coordination, and dissemination function. The Fund also provides a development function for HFN, leveraging private and public funding for the implementation of effective practices. The ability of researchers and practitioners to access program and research funding provides added leverage to each source of funding. The partnership between many regional providers adds credibility to the collaboration, as well as providing economies of scale for HFN activities.

\section{HFN Activities}

The HFN project is being executed in three phases, each providing the foundation for the next.

\section{Phase One-Seminar Series}

An ongoing seminar series has provided a regular forum for practitioner-researcher exchange around common interests. The two-hour monthly sessions (offered for continuing education credits) take place within one of the housing communities and 
are coordinated by university faculty. The goals of the first year's series"Children's Mental Health in the Context of Development', were: (i) to build provider knowledge in developmental psychopathology and children's mental health; (ii) to introduce the concept of evidence-based practice in children's mental health; and (iii) to introduce university faculty to the provider community. Each session focused on a developmental stage and related behavioral and emotional concerns. For example, sessions on school-age children incorporated presentations on developmental tasks at school age, learning difficulties, conduct problems, and childhood depression and anxiety disorders.

Presenters addressed prevention, identification, diagnosis and treatment, and offered concrete strategies for case managers and other housing staff (including teachers, daycare providers, and administrators) to implement with children and families. Providers were encouraged to bring case material for discussion and sessions often included collaborative problem-solving around specific challenges. Some themes cut across development, for example, the identification and promotion of resilience in children, parent-child relationships, and enhancing school/daycarefamily communication. In particular, the concepts of evidence-based practice in children's mental health were infused throughout the training series. Participants were introduced to conceptual and methodological issues with regard to evidencebased practice (e.g., the use of randomized trials to demonstrate efficacy or effectiveness of a practice) and to the extant databases that provide information on effective practices (e.g., SAMHSA's National Registry of Evidence-based Programs and Practices; NREPP).

Thus far, 21 seminar sessions have been conducted, and the series continues toward the end of its second year. Over 100 staff from the 17 agencies attended, with an average of 40 participants each month. Satisfaction surveys completed anonymously by participants at the end of each session indicated that the vast majority of participants found the training informative and useful, with many participants reporting sharing the training materials with colleagues. Each training session was videotaped and DVDs are being distributed to all sites so that staff unable to attend can still have access to the series.

\section{Phase Two-Assessing Needs and Building a Research and Practice Agenda}

The goal of Phase Two was the development of a research and practice agenda based on a psychosocial needs assessment process (Gewirtz, Hart-Shegos, \& Medhanie, in press). The needs study was initiated by the providers; researchers analyzed the data, and the partners developed program and research priorities together. The goals of the needs assessment were (i) to understand the psychosocial status of resident children and families and (ii) to gauge provider agencies' resources and needs in supporting families. As noted earlier, results indicated a significant incidence of child behavior problems, and of trauma-related internalizing difficulties. The need to support parenting was evidenced by the significant incidence of resident families' involvement in the child protection system for child maltreatment as well as by staff concerns raised during the seminar series. Data further highlighted the need to pay attention to factors influencing families' 
engagement in prevention and treatment services. For example, despite significant concerns about children's mental health, both parents and providers reported families' lack of engagement in, or access to traditional mental health services.

Feedback on the needs assessment data was presented to the HFN Advisory Committee, as well as at several other HFN meetings, in order to maximize provider access to the findings. Suggestions for "next steps" were solicited from the Advisory Committee, and from individual providers via email. The key practice priorities were identified as: (i) prevention strategies to address children's behavior problems, (ii) supporting parenting, and (iii) increasing access to mental health treatment for children in general, and in particular, trauma-focused treatment. These practice priorities were congruent with and lengthened an earlier priority list that the Advisory Committee had generated, which included: mental health training for staff, on-site clinical consultation, therapeutic, and crisis intervention services. In light of the barriers noted previously, the consensus was that on-site services would be preferable to community mental health referrals. In addition, the priority for prevention services was to select and implement practices that could feasibly be sustained in the HFN agency settings (i.e., cost-efficient services that could be delivered by advocates or case managers). The Advisory Committee decided to focus initially on addressing the needs of school-age children (5-12), as they represented the largest age group in the housing communities.

The findings of barriers to treatment access and engagement engendered several research questions related to the investigation of factors associated with the engagement of formerly homeless families in mental health services, and the utility of implementing tailored, evidence-based interventions within this context. Given the historically limited access to and engagement in mental health services of this population, questions about feasibility of implementing evidence-based practices, fidelity to best practice models, and client acceptability of such practices were priorities. The priority-setting process of the HFN coincided with the opportunity to participate in two federal grants, which constitute the implementation phase of the partnership.

\section{Phase Three-Implementation}

Two Phase Three projects are in their early stages (see Table 1 for a summary of prevention and treatment interventions in adaptation or implementation).

The first project is the adaptation and implementation of trauma-focused interventions for children in family supportive housing communities. Thus, the HFN is a partner in a SAMHSA-funded National Child Traumatic Stress Network Community Treatment and Services Center (the Minnesota Child Response Center, at the University of $\mathrm{MN}$ ) whose goal is to adapt and disseminate evidence-based trauma interventions for homeless and formerly homeless children and families. Grant funding provides for training in, and adaptation and dissemination of evidence-based interventions for school-aged children in HFN agencies who are exhibiting trauma-related internalizing and externalizing behaviors. This project partners housing sites, shelters, community mental health clinics and public institutions (schools, county, and state services) to increase access to care for 
Table 1 Summary of evidence-based prevention and treatment interventions under adaptation or implementation by healthy families network provider agencies

\begin{tabular}{|c|c|c|c|c|}
\hline $\begin{array}{l}\text { Intervention } \\
\text { name }\end{array}$ & $\begin{array}{l}\text { Target } \\
\text { population }\end{array}$ & $\begin{array}{l}\text { Modifications from } \\
\text { original intervention }\end{array}$ & $\begin{array}{l}\text { Stage of } \\
\text { implementation }\end{array}$ & $\begin{array}{l}\text { Number of agencies } \\
\text { participating }\end{array}$ \\
\hline $\begin{array}{l}\text { Trauma- } \\
\text { focused } \\
\text { cognitive } \\
\text { behavioral } \\
\text { therapy }\end{array}$ & $\begin{array}{l}\text { Traumatized } \\
\text { children in } \\
\text { supportive } \\
\text { housing }\end{array}$ & $\begin{array}{l}\text { Address specific needs of } \\
\text { homeless populations } \\
\text { (e.g., provide home- } \\
\text { based therapy; add } \\
\text { significant engagement } \\
\text { component) }\end{array}$ & Dissemination & $\begin{array}{l}\text { Available to all HFN } \\
\text { agencies }\end{array}$ \\
\hline $\begin{array}{c}\text { Parenting } \\
\text { through } \\
\text { change }\end{array}$ & $\begin{array}{l}\text { Formerly } \\
\text { homeless } \\
\text { parents of } \\
\text { school-age } \\
\text { children }\end{array}$ & $\begin{array}{l}\text { Curriculum adaptations } \\
\text { specific to homelessness } \\
\text { and trauma; cultural } \\
\text { modifications to reflect } \\
\text { diverse population. } \\
\text { Testing feasibility, } \\
\text { client acceptability and } \\
\text { fidelity }\end{array}$ & $\begin{array}{l}\text { Feasibility } \\
\text { pilot trial }\end{array}$ & Eight agencies \\
\hline Early risers & $\begin{array}{l}\text { Formerly } \\
\text { homeless } \\
\text { families with } \\
\text { 5- to 12- } \\
\text { year-old } \\
\text { children }\end{array}$ & $\begin{array}{l}\text { Implementing as a } \\
\text { selective, rather than } \\
\text { indicated prevention } \\
\text { program. Test goodness- } \\
\text { of-fit for client-centered, } \\
\text { variable-prescriptive/ } \\
\text { tailored model. Examine } \\
\text { engagement and client } \\
\text { outcomes }\end{array}$ & $\begin{array}{l}\text { Randomized } \\
\text { effectiveness } \\
\text { trial }\end{array}$ & $\begin{array}{l}\text { Sixteen agencies } \\
\text { (randomly assigned to } \\
\text { eight early risers and } \\
\text { eight community } \\
\text { comparison sites) }\end{array}$ \\
\hline
\end{tabular}

traumatized homeless and formerly homeless children. Trauma-focused cognitive behavioral therapy (Cohen et al. 2000) is adapted for formerly homeless children suffering from posttraumatic stress disorder and traumatic distress. Community mental health clinic professionals are trained in and provide onsite trauma-focused cognitive behavioral therapy to families in supportive housing communities.

To prevent and address children's conduct problems, a selective prevention group parenting program, Parenting Through Change (PTC), is currently being adapted and manualized for formerly homeless parents whose children have histories of trauma, including exposure to violence and abuse (Forgatch and DeGarmo 1999; Gewirtz, Forgatch, \& Wieling, in press). PTC applies the principles of Oregon Parent Management Training (e.g., Patterson 2005) and has been proven effective in preventing and reducing conduct problems among children of separating and divorcing mothers. In the original efficacy study, children whose mothers participated in the PTC groups showed significantly fewer behavioral and emotional disruptions over a three year period following the group, than did randomly selected control group children (DeGarmo et al. 2004; Forgatch and DeGarmo 1999). Here, PTC will be implemented for families at-risk for parenting disruptions due to homelessness and trauma experiences. Several HFN staff members participate in the adaptation of the PTC curriculum. PTC groups facilitated by advocates, and 
supervised by mental health professionals, will be piloted in eight sites to assess their feasibility and acceptability in supportive housing communities.

A second Phase Three project is an NIMH-funded effectiveness trial of the Early Risers Skills for Success program (August et al. 2001). Early Risers is an intensive, two-year long, multi-component selective prevention program, targeting the negative psychosocial processes leading to chronic and serious conduct problems. Prevention components include child programming (after-school and summer camp activities to build social and academic skills), parenting programming (parent training, family nights), and family support/case management. The program has proven successful at preventing and ameliorating child behavior problems when implemented in schools, homes, and community centers, with diverse populations, using a standard level of involvement (August et al. 2001). The current study investigates the integration of this evidence-based prevention program into a supportive housing context, using a tailored, client-centered approach that offers different components of the program based on parent, child, and family level of need. The HFN providers implement the program with core program staff (known as family advocates), who are shared among the HFN provider sites, thus making the program more feasible, cost effective, and sustainable. The Family Housing Fund was successful in raising "matching" funds from local foundations and corporations for additional program costs for HFN provider sites that research funding did not cover (i.e., those sites randomized to the community comparison condition).

In addition to the two projects described above, extra funding through foundation support to the Family Housing Fund has enabled the HFN to hire a full-time licensed mental health professional to provide consultation, coordination, and crisis mental health services at all provider agencies. Addressing the needs of infants, toddlers, and preschoolers represents the next stage of the HFN partnership agenda. The first project in this next stage will be a comprehensive study of the needs of this population, particularly focused on the developmental status and adjustment of birth to 4-year-olds, parent-child relationships, and childcare status. Data from this study will be used by the HFN partners in order to determine program and research priorities for this age group.

\section{Discussion}

The ongoing Healthy Families Network partnership has brought gains in knowledge and practice to both researchers and practitioners. The opportunity for communication between researchers and practitioners through the Phase One seminar series was an important prelude to working together in evidence-based practice implementation and research involving client populations (see also Fisher and Ball 2002, regarding the importance of shared educational opportunities for developing community-university partnerships). Researchers developed an enriched understanding of the real pressures facing supportive housing organizations, and of the remarkable depth of expertise of case managers and advocates who are supporting client families with multiple challenges. 
Community practitioners also have reported benefiting from the partnership through increased knowledge and understanding of children's mental health and development, research, and its use in evidence-based practice with high-risk families, as well as through increased access to university expertise and resources. The increased awareness is evident in the enthusiasm and involvement of HFN agencies in the prevention and intervention projects. (For example, 16 of the 17 agencies opted to participate in the randomized trial of Early Risers, and although the project is only just beginning, recruitment of eligible families is above $90 \%$ in both Early Risers and comparison sites, a reflection of the enthusiasm and followthrough of the housing staff who were asked to introduce the project to resident families.)

\section{Challenges}

The primary challenges to this university-community partnership fell into three categories: (i) provider resources, (ii) perceptions of research, and (iii) implementation of evidence-based practices. With regard to provider resources, the challenges facing homelessness providers include high rates of staff turnover and burnout, and a dearth of financial resources to support programming for homeless families. Although attendance at the seminar series remained remarkably high throughout the first year, many agencies commented that they could not always send the staff they wanted because they did not have the resources to provide coverage while staff was attending training. Producing and distributing DVDs of all the trainings enables greater access for more staff.

Lack of provider resources also has implications for the implementation of the evidence-based practices. In this case, having an intermediary agency (the Family Housing Fund) to facilitate the partnership and take on its administrative burdens (communication, coordination, and development) has been critical to its success. The relationship between the Fund and the provider agencies has been built over many years, significantly predating the HFN. The Fund has also recently raised grant monies disbursed to agencies specifically to address the resource challenges of high staff turnover and burnout (for example, to cover staff retreats, case manager support groups, etc.).

The second set of challenges related to perceptions of research. Concerns about the potentially intrusive nature of research with vulnerable populations (particularly with methods that extend beyond the use of self-report measures, such as observational or biological data) were raised by agency staff and resolved through ongoing dialogue, and in some cases, modifications to the research process. Concerns were also raised about potential inequities in randomized trials. The HFN partners engaged in a lengthy discussion process, over several months, to reach a consensus about their support for randomized control trials. Though these are generally considered the "gold standard" for prevention researchers (Flay et al. 2005), there is understandable concern about randomized trials on the part of communities, particularly those with disenfranchised populations who have historically been exploited in research. However, 16 out of $17 \mathrm{HFN}$ provider 
agencies chose to participate in the randomized controlled effectiveness trial of Early Risers.

Researchers always met with practitioners in their housing agencies, and were transparent about the data collection and randomization processes. Resolving concerns about research has been an ongoing process requiring balancing scientific integrity in the research process with community buy-in and willingness to participate. Again, the presence of an intermediary agency to facilitate the partnership has greatly improved the resolution of potential conflicts. Within the Early Risers prevention trial in particular, clearly delineating the boundaries between research and practice, and the roles of the university and the community organizations (the intermediary and the agencies) has been critical and has taken place over many meetings in the community. Ongoing, lengthy, and direct communication has been critical in order to ensure an authentic partnership, and to address some of the most sensitive challenges: ensuring that research (i) is perceived as empowering and not exploitative, (ii) is driven by community needs, and (iii) results in improved outcomes and sustainable practices for families and housing communities. In this collaboration, both practitioners and researchers have agreed that the partnership is worthwhile only insofar as it results in empowering, sustainable, and health-promoting practices for children, families, and providers.

Several researchers have documented the challenges to implementing evidencebased practices in community settings (e.g., Hoagwood et al. 2001). We have found that much of the challenge to implementation lies in the flexibility of the intervention and the intervenors. For example, providers and researchers working on the Parenting Through Change curriculum (including the program developer) have defined and agreed on the parameters for adaptation, (i.e., what changes can and cannot be made) and the importance of fidelity. Feasibility trials of the intervention will include observational assessments of fidelity coded with the developer. In the case of Early Risers, advocates "shared" by agencies and hired through the intermediary agency deliver the program in close coordination with housing case managers. A key challenge in this implementation is the coordination of services between housing case managers and Early Risers advocates.

The challenges of implementing ongoing services with a transient population of homeless families are somewhat mitigated in these supportive housing agencies, where the average length of stay is 2 years; nonetheless, we are implementing retention strategies, such as providing meals, babysitting, and compensation for participation in group activities (and research assessments), and multiple strategies for maintaining contact with families. Ultimately, a key indicator of uptake of best practices will be the degree to which housing staff and residents reach consensus on their importance for promoting mental health in formerly homeless children. Feasibility and effectiveness trials offer an opportunity to answer research questions about implementation and dissemination of best practices, but they also offer community providers and residents an opportunity to participate in the adaptation and testing of best practices, to gauge the "fit" for their population. Sustainability of practices is therefore predicated on their perceived value and significance, the resources required to implement them, and their success in changing outcomes. 
Moving the Field Forward: Developing a Blueprint for Promoting Mental Health among Children in Family Supportive Housing

Current criteria that limit funding for supportive housing to households with repeat and/or long episodes of homelessness, chronic mental illness, and/or substance abuse would indicate that children in supportive housing communities may be particularly vulnerable for later psychopathology. Moreover, the highest risk families often have low utilization of traditional, clinic-based mental health resources (Bhui et al. 2006; Buckner and Bassuk 1997; North and Smith 2006; Zima et al. 1996). Although stable family housing with subsidies is undoubtedly a necessary condition for ending homelessness, it may not be sufficient for ensuring children's mental health. The availability of services in family supportive housing, however, affords the opportunity to offer a continuum of care for children, anchored by the supportive housing community. The continuum of care begins with evidencebased prevention programs that strengthen protective processes (e.g., social and peer competence, effective parenting, intellectual skills; Masten 2001; Masten and Gewirtz 2006) and that can be effectively delivered by paraprofessionals. For children who meet diagnostic criteria for psychiatric disorders, housing case managers or advocates who are sophisticated brokers of mental health services can help facilitate referrals to onsite or community-based mental health professionals.

The Healthy Families Network project provides an emerging example of the ways in which supportive housing providers and researchers can develop partnerships to promote children's well being. The partnership advances both practice and research. In the practice world, direct service providers rarely have the time or resources to stay abreast of research findings and to apply them in their everyday work, or to identify access and implement an infrastructure for delivering best practice prevention and treatment interventions. Through the HFN partnership, a group of providers has access to relevant research findings in "real time," and both providers and researchers have an ongoing vehicle for communication.

For both prevention researchers and supportive housing providers, there is a compelling need to learn whether and how existing evidence-based programs might feasibly be utilized in housing communities for vulnerable families who historically have had low access to prevention or treatment. This partnership affords researchers the opportunity to study prevention processes and programs in communities serving high-risk families, and in particular, to investigate questions about families' engagement in services (McKay et al. 1998), and about tailoring interventions to the needs and preferences of clients (Collins et al. 2004)_critical for ensuring the effective use of service resources.

Further research is needed to delineate the mechanisms underlying and influencing the adjustment and development of formerly homeless children in supportive housing. Although comprehensive prevention programs have been shown to be effective across settings and high-risk populations, research is needed to investigate whether embedding evidence-based practice in supportive housing communities can increase family and residential stability. Several researchers have suggested that effectively targeting key risk factors associated with homelessness is critical to ending homelessness (e.g., Gaubatz 2001; Shinn et al. 2006). Effective 
prevention and treatment interventions that target these key risk factors among highrisk children in supportive housing hold some promise for preventing homelessness in future generations.

Acknowledgments I would like to acknowledge the Family Housing Fund, Hart-Shegos and Associates, and the agencies comprising the Healthy Families Provider Network for the valuable partnership and work to support formerly homeless children and families. I thank in particular: Kevin Hardwick, Ellen Hart-Shegos, Sharon Henry-Blythe, Moira Gaidzanwa, Beth Haukebo, Pam Zagaria, and Tom Fulton, for their helpful comments on earlier versions of this manuscript.

\section{References}

Anooshian, L. J. (2005). Violence and aggression in the lives of homeless children: A review. Aggression and Violent Behavior, 10(2), 129-152.

August, G. J., Realmuto, G. M., Hektner, J. M., \& Bloomquist, M. L. (2001). An integrated components preventive intervention for aggressive elementary school children: The early risers program. Journal of Consulting and Clinical Psychology, 69(4), 614-626.

August, G. J., Winters, K., Realmuto, G. M., Tarter, R., Perry, C., \& Hektner, J. M. (2004). Moving evidence-based drug abuse prevention programs from basic science to practice: "Bridging the efficacy-effectiveness interface.' Substance Use and Misuse, 39(10), 2017-2053.

Bassuk, E. L., Weinreb, L. F., Buckner, J. C., Browne, A., Salomon, A., \& Bassuk, S. S. (1996). The characteristics and needs of sheltered homeless and low-income housed mothers. Journal of the American Medical Association, 276(8), 640-646.

Bassuk, E. L., Weinreb, L. F., Dawson, R., Perloff, J. N., \& Buckner, J. C. (1997). Determinants of behavior in homeless and low-income housed preschool children. Pediatrics, 100(1), 92-100.

Bassuk, E. L., Perloff, J. N., \& Dawson, R. (2001). Multiply homeless families: The insidious impact of violence. Housing Policy Debate, 12(2), 299-319.

Bhui, K., Shanahan, L., \& Harding, G. (2006). Homelessness and mental illness: A literature review and a qualitative study of perceptions of the adequacy of care. International Journal of Social Psychiatry, 52(2), 152-165.

Buckner, J. C., \& Bassuk, E. L. (1997). Mental disorders and service utilization among youths from homeless and low-income housed families. Journal of the American Academy of Child \& Adolescent Psychiatry, 36(7), 890-900.

Burt, M., Aron, L., Douglas, T., Valente, J., Lee, E., \& Britta, I. (1999). Homelessness: Programs and the people they serve. Washington, DC: Urban Institute Press.

Burt, M., Aron, L. Y., Lee, E., \& Valentine, J. (2001). Helping America's homeless: Emergency shelter or affordable housing? Washington, DC: Urban Institute Press.

Cohen, J., Mannarino, A., Berliner, L., \& Deblinger, E. (2000). Trauma-focused cognitive behavioral therapy for children and adolescents. An empirical update. Journal of Interpersonal Violence, 15(11), 1202-1223.

Collins, L. M. V., Murphy, S. A. V., \& Bierman, K. L. V. (2004). A conceptual framework for adaptive preventive interventions. Prevention Science, 5(3), 185-196.

Corporation for Supportive Housing (2005). Description of supportive housing. Retrieved December 15, 2005, from www.csh.org. .

Culhane, D. P., Metreaux, S., \& Hadley, T. (2002). Supportive housing for homeless people with severe mental illness. LDI Issue Brief, 7(5), 1-4.

DeGarmo, D. S., Patterson, G. R., \& Forgatch, M. S. (2004). How do outcomes in a specified parent training intervention maintain or wane over time? Prevention Science, 5(2), 73-89.

Fisher, P., \& Ball, T. (2002). The indian family wellness project: An application of the tribal participatory research model. Prevention Science, 3(3), 235-240.

Flay, B., Biglan, A., Boruch, R. F., Castro, F. G., Gottfredson, D., Kellam, S., et al. (2005). Standards of evidence: Criteria for efficacy, effectiveness and dissemination. Prevention Science, 6(3), 151-175.

Forgatch, M. S., \& DeGarmo, D. S. (1999). Parenting through change: An effective prevention program for single mothers. Journal of Consulting and Clinical Psychology, 67, 711-724. 
Gaubatz, K. T. (2001). Family homelessness in Britain: More than just a housing issue. Journal of Children and Poverty, 7(1), 3-22.

Gewirtz, A. H., \& Edleson, J. (in press). Young children's exposure to adult domestic violence: Towards a developmental risk and resilience framework for research and intervention. Journal of Family Violence.

Gewirtz, A. H., Forgatch, M. S., \& Wieling, E. (in press). Parenting practices and children's recovery in the aftermath of trauma: A conceptual framework for research and preventive interventions. Journal of Marital and Family Therapy.

Gewirtz, A. H., Hart-Shegos, E., \& Medhanie, A. (in press). Psychosocial status of homeless children and youth in family supportive housing. American Behavioral Scientist.

Hanrahan, P., McCoy, M. L., Cloninger, L., Dincin, J., Zeitz, M. A., Simpatico, T. A., et al. (2005). The mothers' project for homeless mothers with mental illnesses and their children: A pilot study. Psychiatric Rehabilitation Journal, 28(3), 291-294.

Hoagwood, K., Burns, B. J., Kiser, L., Ringeisen, H., \& Schoenwald, S. K. (2001). Evidence-based practice in child and adolescent mental health services. Psychiatric Services, 52, 1179-1189.

Hopper, K., \& Barrow, S. M. (2003). Two genealogies of supported housing and their implications for outcome assessment. Psychiatric Services, 54(1), 50-54.

Hughes, J. N. (2003). Commentary: Participatory action research leads to sustainable school and community improvement. School Psychology Review, 32(1), 38-43.

Kidd, S. A., \& Kral, M. J. (2005). Practicing participatory action research. Journal of Counseling Psychology, 52(2), 187-195.

Lipton, F. R., Siegel, C., Hannigan, A., Samuels, J., \& Baker, S. (2000). Tenure in supportive housing for homeless persons with severe mental illness. Psychiatric Services, 51(4), 479-486.

Masten, A. (2001). Ordinary magic: Resilience processes in development. American Psychologist, 56(3), $227-238$.

Masten, A., \& Gewirtz, A. (2006). Vulnerability and resilience. In D. Philips \& K. McCartney (Eds.), Blackwell handbook of early childhood development (pp. 22-43). Oxford, England: Blackwell Publishing.

Masten, A. S., Miliotis, D., Graham-Bermann, S. A., Ramirez, M., \& Neemann, J. (1993). Children in homeless families: Risks to mental health and development. Journal of Consulting and Clinical Psychology, 61(2), 335-343.

McKay, M. M., Stoewe, J., McCadam, K., \& Gonzales, J. (1998). Increasing access to child mental health services for urban children and their caregivers. Health and Social Work, 23, 9-15.

McQuistion, H. L., Finnerty, M., Hirschowitz, J., \& Susser, E. S. (2003). Challenges for psychiatry in serving homeless people with psychiatric disorders. Psychiatric Services, 54(5), 669-676.

Nolan, C., ten Broeke, C., Magee, M., \& Burt, M. R., (2005). The family permanent supportive housing initiative: Family history and experiences in supportive housing. Washington, DC: Urban Institute.

North, C. S., \& Smith, E. M. (2006). A systematic study of mental health services utilization by homeless men and women. International Journal of Social Psychiatry, 52(2), 152-165.

Olds, D. (2002). Prenatal and infancy home visiting by nurses: From randomized trials to community replication. Prevention Science, 3(3), 153-172.

Patterson, G. R. (2005). The next generation of PMTO models. Behavior Therapist, 28(2), 25-32.

Rafferty, Y., \& Shinn, M. (1991). The impact of homelessness on children. American Psychologist, 46(11), 1170-1179.

Schinka, J., Francis, E., Hughes, P., LaLone, L., \& Flynn, C. (1998). Comparative outcomes and costs of inpatient care and supportive housing for substance-dependent veterans. Psychiatric Services, 49, 946-950.

Shinn, M., Rog, D. J., \& Culhane, D. P. (2006). Family homelessness: Background research findings and policy options. Washington, DC: Interagency Council on Homelessness.

Shinn, M., Weitzman, B. C., Stojanovic, D., Knickman, J. R., Jiminez, L., Duchon, L., et al. (1998). Predictors of homelessness from shelter request to housing stability among families in New York City. American Journal of Public Health, 88(11), 1651-1657.

Spoth, R. L., \& Redmond, C. (2002). Project family prevention trials based in community-university partnerships: Toward scaled-up preventive interventions. Prevention Science, 3(3), 203-221.

Tolan, P., Keys, C., Chertok, F., \& Jason, L. (Eds.) (1990). Researching community psychology: Issues of theories and methods. Washington, DC: American Psychological Association.

Tsemberis, S. (1999). From streets to homes: An innovative approach to supported housing for homeless adults with psychiatric disabilities. Journal of Community Psychology, 27(2), 225-241. 
U.S. Conference of Mayors (2004). A status report on hunger and homelessness. Washington, DC: U.S. Conference of Mayors.

Vostanis, P., Grattan, E., \& Cumella, S. (1998). Mental health problems of homeless children and families: Longitudinal study. British Medical Journal, 316(7135), 899-902.

Vostanis, P., Grattan, E., Cumella, S., \& Winchester, C. (1997). Psychosocial functioning of homeless children. Journal of the American Academy of Child and Adolescent Psychiatry, 36(7), 881-889.

Weinreb, L., Goldberg, R., Bassuk, E., \& Perloff, J. (1998). Determinants of health and service use patterns in homeless and low-income housed children. Pediatrics, 102(3), 554-562.

Weissberg, R. P., \& Greenberg, M. T. (1998). Prevention science and collaborative community action research: Combining the best from both perspectives. Journal of Mental Health, 7, 479-492.

Zima, B. T., Wells, K. B., Benjamin, B., \& Duan, N. (1996). Mental health problems among homeless mothers: Relationships to service use and child mental health problems. Archives of General Psychiatry, 53, 332-338. 